\title{
High-precision online sensor condition monitoring of industrial oils in service for the early detection of contamination and chemical aging
}

\author{
Mauntz, Manfred*; Kuipers, Ulrich*; Gegner, Jürgen*** \\ ${ }^{*}$ cmc Instruments $\mathrm{GmbH}$; ${ }^{* *}$ South Westphalia University of Applied Sciences; *** University of Siegen \\ * Hauptstraße 388, D-65760 Eschborn; ${ }^{* *}$ Haldener Straße 182, D-58095 Hagen; ${ }^{* * *}$ Paul-Bonatz-Straße \\ 9-11, D-57076 Siegen
}

\begin{abstract}
A new online diagnostics system for the continuous condition monitoring of, e.g., lubricating and insulating oils in industrial gearboxes or transformers is presented. Characteristic features of emerging component damage, such as wear or chemical aging, are identified in an early stage. The OilQSens ${ }^{\circledR}$ Sensor effectively controls the proper operation conditions of bearings or gears. The online diagnostics system measures components of the specific complex impedance of oils. For instance results metal abrasion due to wear debris, broken oil molecules, forming acids or oil soap in an increase of the electric conductivity, which directly correlates with the degree of pollution in the oil. The dielectrical properties of the oils are particularly determined by the water content that becomes accessible via an additional accurate measurement of the dielectric constant, in the simplest case for products not enriched with additives. For additivated oils, statements on the degradation of additives can also be derived from changes in the dielectric constant. For an efficient machine utilization and targeted damage prevention, the new OilQSens ${ }^{\circledR}$ online condition monitoring system allows for timely preventative maintenance on demand rather than in rigid inspection intervals. The determination of impurities or reduction in the quality of the oil and the quasi continuous evaluation of wear and chemical aging follow the holistic approach of a real-time monitoring of a change in the condition of the oil-machine system. The measuring signals are transmitted to a web-based condition monitoring system via LAN, WLAN or serial interfaces of the sensor system. Monitoring of the damage mechanisms during proper operation below the tolerance limits of the components enables specific preventive maintenance independent of rigid inspection intervals. The function of the online condition monitoring system is successfully tested on a bearing and gear test rig applying various stress cycles.
\end{abstract}

\section{Principle of OilQSens ${ }^{\circledR}$}

With the OilQSens ${ }^{\circledR}$ unit, components of the complex impedances $X$ of oils, in particular the specific electric conductivity $\kappa$ and the relative permittivity $\varepsilon_{r}$ as well as the oil temperature $T$ are measured [1-3]. The values $\kappa$ and $\varepsilon_{\mathrm{r}}$ are determined independently of each other. Fig. 1 shows the sensor element with its triple plate design.

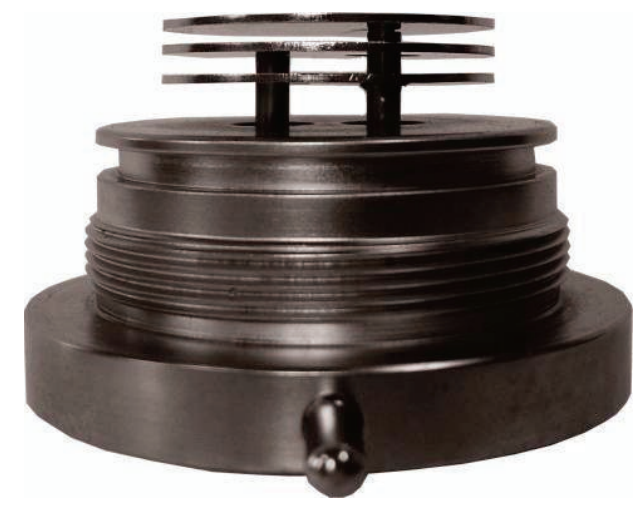

Fig. 1: Sensor element with triple plate design.

Oils are electrical non-conductors. The electrical residual conductivity of pure oils lies in the range below $1 \mathrm{pS} / \mathrm{m}$. For comparison, the electrical conductivity of the electrical non-conductor distilled water is larger by six orders of magnitude. 
Abrasive (metallic) wear, ions, broken oil molecules, acids, oil soaps, etc., cause an increase of the oil conductivity $\kappa$. It rises with increasing ion concentration and mobility. The electrical conductivity of almost all impurities is high compared to the extremely low corresponding property of original pure oils. A direct connection between the electrical conductivity and the degree of contamination of oils is found. An increase of the electrical conductivity of the oil in operation can thus be interpreted as increasing wear or contamination of the lubricant. The aging of the oil is also evident in the degradation of additives. The used additives reveal high conductivity compared to oil.

The consumption of the additives is reflected in a reduction of the electrical conductivity and permittivity of the oil. The gradient, i.e. the time derivative, of the conductivity or the dielectric constant progression respectively represents a measure of the additive degradation and consumption. The full additive degradation is indicated by the slope of zero (bathtub curve). Then the measurement signal increases further with increasing pollution, water entry, etc.

Ion mobility and thus electrical conductivity $\kappa$ are dependent on the internal friction of the oil and therefore also on its temperature. The conductivity $\kappa$ of the oil increases with temperature. The type of pollution and its temperature dependence cannot be assumed to be known. To improve the comparability of measurements, a self-learning adaptive temperature compensation algorithm is necessary. An integral alteration of the oil quality can then be assessed by the temperature compensated conductivity value, whereas the type of contamination is not determinable.

The relative permittivity is measured with the same basic sensor arrangement as used for the determination of the electrical conductivity.

\section{Trial of the Sensor Performance on a Rolling Bearing Test Rig}

Various stress cycles are run and speeds and torques measured on a bearing and gear test rig, shown in Fig. 2.

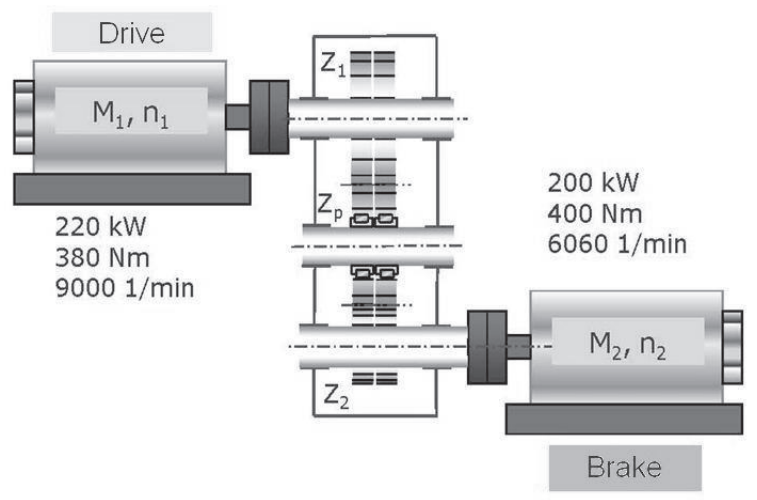

Fig. 2: Scheme of the used bearing and gear test rig.

In the case of an initially low stress, the electric conductivity increases linearly with time: it is to be expected that the low bearing wear in this range also increases with time.

During the necessary shutdown and run-up of the drive machine to $151 \mathrm{Nm}$, the conductivity is practically constant. After switching over to the higher load, the oil conductivity increases strongly. Here the effect of bearing run-in (shakedown) is shown as reduction in the conductivity increase. After switching off the test gear, the oil conductivity decreases markedly. This clearly underlines the influence of the additives. During the loading phases, more impurities per time unit are produced than can be bound by the additives. After shutting down the test rig, such oil contamination no longer occurs while the effect of additives still continues.

At the beginning of the stress, see Fig. 4, there is a run-in (shakedown) of the bearing. There it comes to small changes in the structures of individual components and a reduction in the quality of the machine. The stress will be increased to all components of the machine (like bearing) after the run-in and further more small stress at the bearing. The quality of the machine becomes significantly worse. Just in the end, shortly before the switch off, the connected measurement system of vibration analysis responds, long after the damage started.

Fig. 3 shows the temperature-compensated oil conductivity with running time during the rig test. 


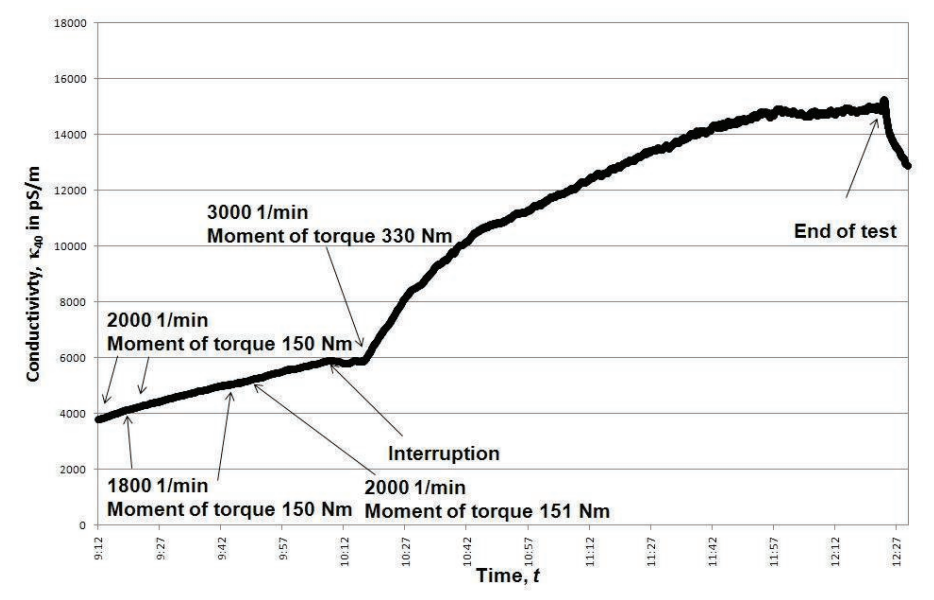

Fig. 3: Course of temperature compensated conductivity of the oil.

Fig. 4 qualitatively describes the quality of the test machine during the entire course of the experiment.

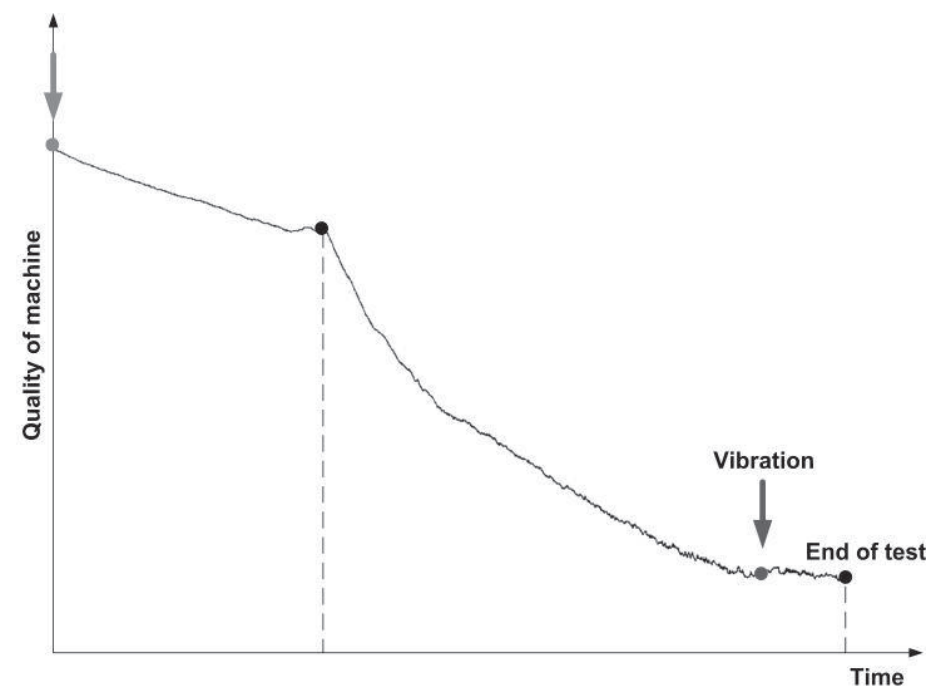

Fig. 4: Quality of the machine during the rig test.

Fig. 5 shows the inner ring of the failed planetary gear bearing with massive damage of the raceway at the end of the trial.

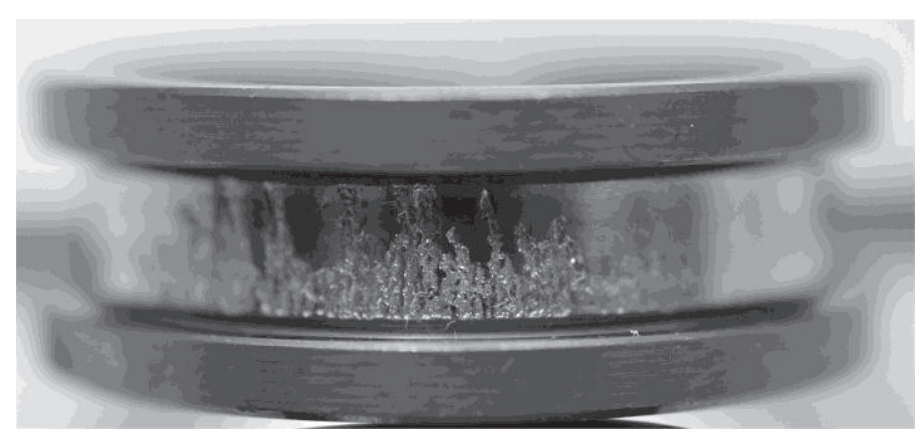

Fig. 5: Spalled inner ring raceway of the tested cylindrical roller bearing. 
Fig. 6 displays the gradient of the electrical conductivity.

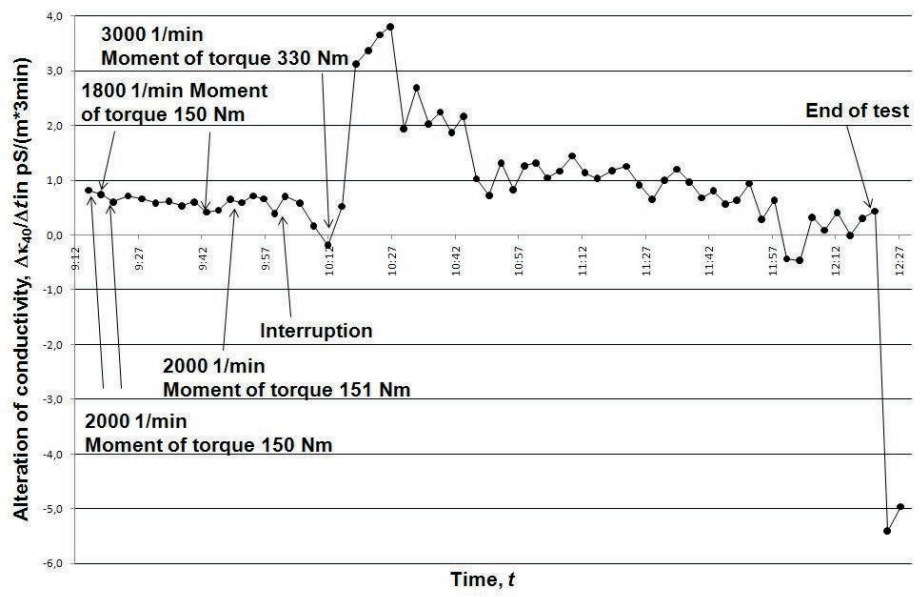

Fig. 6: Gradient of the electrical conductivity.

When starting up with a speed frequency of $2000 \mathrm{~min}^{-1}$ and a torque of $150 \mathrm{Nm}$, a relatively constant alteration of the conductivity from 0.6 to $0.8 \mathrm{pS} /(\mathrm{m} \cdot 3 \mathrm{~min})$ occurs. After increasing the load to $330 \mathrm{Nm}$ at $3000 \mathrm{~min}^{-1}$, the change in conductivity raises up to $3.8 \mathrm{pS} /(\mathrm{m} \cdot 3 \mathrm{~min})$. After the intermediate load increase, the effect on the change of the oil conductivity appears stronger. This may be attributed to the timedependent formation of impurities and changes in bearing stressing as can be expected during the development of spalling. The real-time monitoring of the state change of the oil-machine system allows a specific control of the machine in terms of its wear limit. Improper loading conditions in inadmissible wear ranges can thus be avoided, which results in a more efficient machine utilization.

\section{Approach for Condition Monitoring of Additivated Lubricating Oils}

Fig. 7 schematically shows the temperature compensated time curve of the permittivity of additivated oil continuously contaminated by the addition of wear debris, water or oil acids from chemical aging. Once the additives are consumed, the vanishing shielding effect results in a characteristic re-increase.

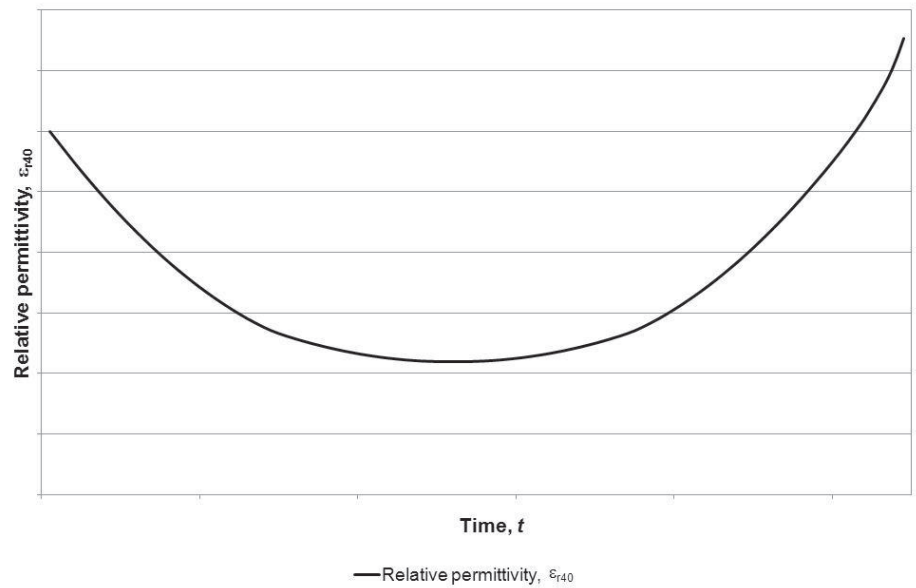

Fig. 7: Temperature compensated permittivity.

The most commercially available particle counters can only detect particles as small as $4 \mu \mathrm{m}$. In a very early stage of wear of bearings, gears, hydraulic cylinders, etc., however, particularly smaller particles are produced. A preventive maintenance lowing, rather than rigid inspection intervals, therefore requires recognition of even the smallest particles. These particles are far more common in the oils of functioning machines than larger ones. Oil aging can be involved in the failure, for instance, of rolling bearings [4]. 


\section{Web-based Decentralized Lubricant Quality Monitoring System}

The integration into a suitable communication structure and the realization of an online monitoring system offers an interesting practice-oriented utilization of the oil sensor system.

Preferred areas of application of the sensor system are energy production and automated technical plants that are operated locally, like e.g. wind turbines, transformer stations, generators, hydraulic systems or gearboxes. Plant employers are interested in continuous automated in vivo examination of the oil quality rather than interrupting the operation for regular sampling. The practical use of the oil sensor system is thus evident. Online oil status monitoring significantly improves the economic and ecological efficiency by increasing operating safety, reducing down times or adjusting oil change intervals to actual requirements. Once the oil quality sensors are installed on the plants, the measuring data can be displayed and evaluated elsewhere. A flexible decentralized monitoring system also enables the analysis of measuring signals and monitoring of the plants by external providers. A user-orientated service ensuring the quantitative evaluation of changes in the oil-machine system, including the recommendation of resulting preventive maintenance measures, relieves plant operators, increases reliability and saves costs.

In a web-based decentralized online oil condition monitoring system, the sensor signals are preferably transferred through the Internet to a database server and recorded on an HTML page as user interface. Following authentication, a simple web browser permits access via the wired or wireless LAN. In case of alarm signals, an immediate automated generation of warning messages, for instance by e-mail or SMS, is possible from any computer with Internet connection. With respect to required actuarial neutral surveys and status monitoring, e.g. of wind turbines, plant operators may also use the quasi-continuous oil sensor system for documentation purposes. Fig. 8 shows the OilQSens ${ }^{\circledR}$ sensor system with communication module.

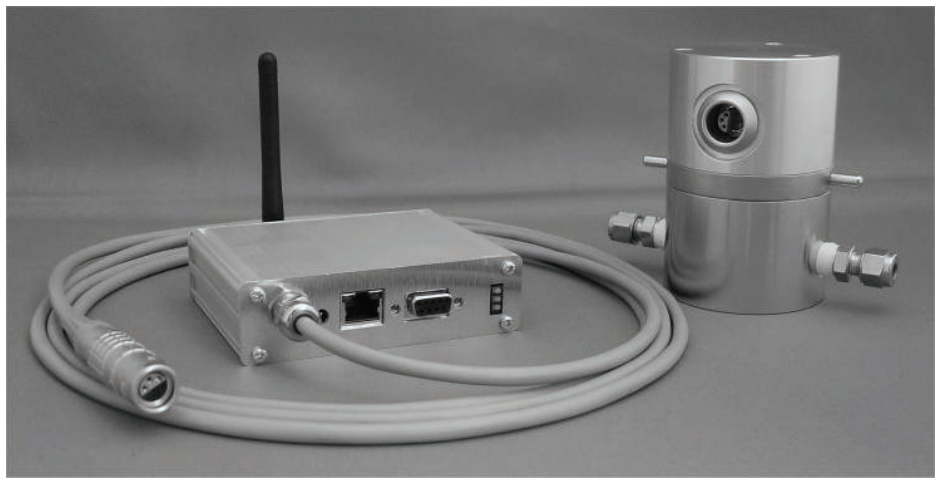

Fig. 8: OilQSens ${ }^{\circledR}$ sensor system with communication module.

\section{Summary}

Rolling bearings, operating partly under mixed friction running conditions, caused e.g. by external (engine) vibrations, experience tribological surface loading. Besides friction influences, abrasive or adhesive wear, damage from the aging lubricant is also of relevance. For instance, tribochemical dissolution of manganese sulphide inclusion lines, which can intersect the steel surface, does occur. This material removal results in a crack-like defect on the contact area, eventually. Permanent control of the chemical condition of the lubricant that can acidify by stressing during operation is thus of high practical significance. Even for the high cleanliness of rolling bearing steels, non-metallic inclusions are unavoidable in the steelmaking process.

The online diagnostics system measures components of the specific complex impedance of oils. For instance, metal abrasion due to bearing wear at the tribological contact, broken oil molecules, acids or oil soap cause an increase in electric conductivity that directly correlates with the degree of pollution of the oil. The dielectrical properties of the oils are especially determined by the water content, which, in the case of products that are not enriched with additives, becomes accessible by an additional accurate measurement of the dielectric constant. In the case of oils enriched with additives, statements on the degradation of additives can also be deduced from recorded changes in the dielectric constant. 
Indication of wear is measured as an integral factor of, e.g., the degree of pollution, oil aging and acidification, water content and the decomposition state of additives, abrasion of the bearings. It constitutes an informative standard of lubricant and material stress as well as the wear of the bearings and gears for the online operative monitoring of components of machines. Additional loading, for instance, by boundary lubrication in rolling-sliding contact (rolling bearings, gears, cams, etc.) causes

the oil to age faster. The oil experiences incipient resinification in roller bearing tests and significant acidification is proven by infrared spectroscopy.

For an efficient machine utilisation and targeted damage prevention, the new OilQSens ${ }^{\circledR}$ online condition monitoring system offers the prospect to carry out timely preventative maintenance on demand rather than in rigid inspection intervals. The determination of impurities or reduction in the quality of the lubricants and the quasi continuous evaluation of the bearing and gear wear and oil aging meet the holistic approach of a real-time monitoring of a change in the condition of the oil-machine system.

The measuring signals can be transmitted to a web-based condition monitoring system via LAN, WLAN or serial interfaces of the sensor system. The monitoring of the tribiological wear mechanisms during proper operation below the tolerance limits of the components then allows preventive, condition-oriented maintenance to be carried out, if necessary, long before regular overhauling, thus reducing outages caused by wear while simultaneously increasing the overall lifetime of the oil-machine system.

On a bearing and gear rig test, various load cycles are run and the function of the online condition monitoring system is tested successfully. The change in the conductivity diagram indicates the current wear mechanisms of a rolling bearing and the deteriorating oil condition in the trial.

\section{References}

[1] J. Gegner, U. Kuipers, M. Mauntz: Ölsensorsystem zur Echtzeit-Zustandsüberwachung von technischen Anlagen und Maschinen. Technisches Messen 77 (2010) 283-292

[2] U. Kuipers M. Mauntz: Ölsensorsystem - Sensorsystem zur Messung von Komponenten der komplexen Impedanz elektrisch gering leitender und nichtleitender Fluide, dessen Realisierung und Anwendung. Patentanmeldung Nr. 102008047 366.9, Anmelder: cmc Instruments $\mathrm{GmbH}$, Deutsches Patentamt, München, Anmeldetag: 15. 9. 2008

[3] U. Kuipers, M. Mauntz: Verfahren, Schaltungsanordnung, Sensor zur Messung physikalischer Größen in Fluiden sowie deren Verwendung. Europäische Patentanmeldung Nr. EP 09000244 , Europäisches Patentamt, München, 9. 1. 2009

[4] J. Gegner und W. Nierlich: Mechanical and Tribochemical Mechanisms of Mixed Friction Induced Surface Failures of Rolling Bearings and Modeling of Competing Shear and Tensile Stress Controlled Damage Initiation. T+S Tribologie und Schmierungstechnik $\underline{58}$ (2011) 10-21 